\title{
Phenotypic and Genotypic Characterization, and Detection of PVL Encoding Gene in Methicillin Resistant Staphylococcus Aureus Strains Isolated From Patients Admitted to a Tertiary Hospital In Kuantan, Malaysia
}

\author{
Mohammad Hanif Bariman ${ }^{a}$, Mohammed Imad A. Mustafa Mahmoud ${ }^{b}$, Hairul Aini binti Hamzah ${ }^{c}$ \\ aDepartment of Microbiology, Faculty of Medicine, Kabul Medical University, 24000 Kabul, Afghanistan. \\ bDepartment of Basic Medical Science, Faculty of Medicine, IIUM, 25200 Kuantan, Pahang, Malaysia. \\ 'Department of Basic Medical Science, Faculty of Medicine, IIUM, 25200 Kuantan, Pahang, Malaysia
}

\section{ABSTRACT}

Introduction: Methicillin-resistant Staphylococcus aureus is globally a major public health threat. Resistance to methicillin originates from a modified protein (PBP2a) encoded by the mecA gene. The PVL gene as an important virulence factor increases the pathogenicity of MRSA. Epidemiology and characteristics of MRSA differ in different geographical regions. This study was conducted to characterize and determine the antibiotic susceptibility profile of MRSA strains isolated from patients in Hospital Tengku Ampuan Afzan, Pahang, Malaysia and to detect the presence of the mecA and PVL genes in the isolates. Materials and methods: In this study a total of 36 isolates of MRSA have been collected during a period of three months ( $1^{\text {st }}$ February $-30^{\text {th }}$ April 2018). The susceptibility pattern of the isolates to ten different commonly used antibiotics were determined and the target genes were addressed by real-time PCR experiment. Results: Based on the identifying criteria, $44.4 \%$ of the isolates were CA-MRSA, and $55.5 \%$ were HA-MRSA. Resistance to oxacillin, cefoxitin and penicillin was $100 \%$, gentamicin $88.8 \%$, erythromycin $33.3 \%$, tetracycline $77.7 \%$, trimethoprim-sulfamethoxazole $61.1 \%$, clindamycin $13.8 \%$, chloramphenicol $11.1 \%$, but no resistant strain of vancomycin was detected. Most of the isolates were resistant to more than three groups of antibiotics. Realtime PCR revealed that all the isolates were mecA positive and 4 isolates were $P V L$-positive. $P V L$-positive strains were CA-MRSA and susceptible to clindamycin. Conclusion: The study confirms multi-drug resistant MRSA in the study area, and shows that resistance to methicillin is mecA mediated. PVL carrier strains were present and related to CA-MRSA strains of the isolates.

KEYWORDS: MRSA, CA-MRSA, HA-MRSA, meCA, PVL

\section{INTRODUCTION}

Infectious diseases make globally the major cause of early deaths. Overgrowing rate of antibioticresistant bacteria have been threatening world population together with the recurrence of those infectious diseases which once had been considered

Corresponding author:

Prof. Dr. Mohammed Imad A. Mustafa Mahmoud Department of Basic Medical Sciences,

Kulliyyah of Medicine,

IIUM Kuantan Campus, 25200 Kuantan,

Pahang, Malaysia

Tel No: +60-19 9297407

Email: imad@iium.edu.my to be under the control mainly in developed countries. The recent drug resistance in bacteria has aroused big concern in the world. ${ }^{1} S$ aureus is part of the normal flora of healthy individuals. ${ }^{2}$ Toxins and exoproteins production is responsible for the pathogenic capability of $S$ aureus. ${ }^{3}$ In addition, the prevalence of $S$ aureus outside of the hospital is another great medical concern. ${ }^{4}$

Although, antibiotics have decreased the risk of $S$ aureus infections, development of resistance to multiple antibiotics has challenged efforts to treat these infections easily and successfully. ${ }^{2} \mathrm{~S}$ aureus firstly, became resistant to penicillin, the finding that caused the introduction of penicillinaseresistant penicillin such as methicillin and oxacillin to 
treat infections caused by these resistant strains. MRSA was detected just two years after the introduction of methicillin in UK. ${ }^{4}$ MRSA strain of $S$ aureus is defined as one that is resistant to the latter group of penicillinase-resistant "betalactams".

Studies show that most of the MRSA strains are resistant to a wide spectrum of antibiotic groups, which are known as multiple-drug resistant MRSA. ${ }^{5}$ Vancomycin is used as the last option to treat MRSA, however, recently there are increasing reports from many countries on resistant to vancomycin. ${ }^{6}$ MRSA is implicated in causing the most common infections of the human body like skin infections, bone and joint infections and respiratory tract infections. Furthermore, MRSA also causes exotoxin-mediated infections. MRSA-induced infections are considered to cause long duration hospital stay, increased health care expenses, and increased the mortality rates. ${ }^{4}$ It has been stated that the improper use of antimicrobial agents is the key factor that helps with the spread of antibioticresistant bacteria. ${ }^{7}$ In MRSA, the main cause of the resistance to beta-lactam antibiotics are a modified protein named penicillin-binding protein 2a (PBP2a). This protein is encoded by the $\operatorname{mec} A$ gene and has lower affinity for penicillin. ${ }^{8}$

There are some staphylococci like $S$ vitulinus, that has the mecA gene, but its presence is not associated with the resistance to beta-lactams. The gene of mecA that can cause the resistance to betalactams is located on a mobile genetic element called Staphylococcal Cassette Chromosome mec (SCCmec), this can be found in strains of Staphylococcus aureus, Staphylococcus epidermidis and Staphylococcus haemolyticus. ${ }^{8}$ However, studies revealed that the resistance to methicillin may not only be mediated by the mecA gene. ${ }^{9}$ In addition, some strains of MRSA often carry Panton-Valentine Leukocidin (PVL) encoding gene. ${ }^{10}$

PVL acquired more importance in the near past because it had been linked with the CA-MRSA infections. PVL is an exotoxin of $S$ aureus that causes apoptosis and has cytotoxic effects on the human neutrophils. $S$ aureus strains harboring the PVL encoding gene rapidly spread and causing serious skin and soft tissue infections. ${ }^{11}$ As the antibiotic susceptibility profile, genetic characteristics and epidemiology of MRSA isolates differ in the different geographical area. Therefore, this study was conducted to define the susceptibility profile of MRSA isolates in the study area, and to look for the presence of mecA and PVL genes in these isolates.

\section{MATERIALS AND METHODS}

In this study, a total of 36 clinical MRSA isolates were collected over a period of 3 months $\left(1^{\text {st }}\right.$ February $-30^{\text {th }}$ April, 2018). The sample was obtained from the Microbiology Laboratory, Pathology Department, Hospital Tengku Ampuan Afzan (HTAA), Pahang, Malaysia. The isolates originated from various types of patients' specimens. Patients were from different wards (surgical ward, orthopaedic ward, obstetrics and gynaecology ward, internal medicine ward, paediatric ward, outpatient department, intensive care unit, cardiology and skin wards). Patients' demographic and clinical data including (the history of hospitalization and surgical operation, medical history and chief complains, date of admission to hospital and the department where the patient was admitted), were collected from the hospital record book.

In this study CA-MRSA, HA-MRSA and MDR strains are defined as follows: CA-MRSA is strain, isolated from healthy individuals, patients in OPD (outpatients department), patients within 48 hours of hospitalization or from those patients who don't have the history of hospitalization or surgical operation during the last three months. HA-MRSA is strain isolated from hospitalized patients or from those who have a history of hospitalization and surgical operation during the last three months. ${ }^{12}$ Multi-drug resistant strains are resistant to three or more groups of antibiotics. ${ }^{13}$ In this study $S$ aureus ATCC 25923 (penicillin-susceptible strain), S aureus ATCC 29213 (penicillin resistant, beta-lactamase positive strain), and MRSA ATCC 35591 (positive for both the mecA and $P V L$ genes) were used as a control or reference strains.

The isolates obtained from HTAA were re-identified and confirmed as MRSA by conventional phenotypic tests, including culture on blood agar, gram stain, catalase test, coagulase test, culture on mannitol salt agar, and resistant profile to oxacillin. Then the antibiotic susceptibility profile and genetic 
characterization of the isolates were tested according to the research objectives. All the isolated strains were tested for antibiotic susceptibility by Kirby-Bauer disc diffusion method, in this test oxacillin $(1 \mu \mathrm{g})$, gentamicin $(10 \mu \mathrm{g})$, erythromycin $(15 \mu \mathrm{g})$, trimethoprimsulfamethoxazole $(1.25 / 23.75 \mu \mathrm{g})$, chloramphenicol $(30 \mu \mathrm{g})$, tetracycline $(30 \mu \mathrm{g})$, vancomycin $(30 \mu \mathrm{g})$, cefoxitin $(30 \mu \mathrm{g})$, clindamycin $(2 \mu \mathrm{g})$ and penicillin's (10U) discs (Oxoid, UK) were used on Mueller-Hinton agar according to the Clinical and Laboratory Standards Institute (CLSI) guidelines. ${ }^{14}$

As the disk diffusion test can only provide limited qualitative details of the susceptibility pattern of MRSA to vancomycin. Therefore, the minimal inhibitory concentration to oxacillin and vancomycin was evaluated by E-test (bioMereiux, USA) for all the isolates as well.

DNA Extraction: The DNA was extracted from the confirmed MRSA isolates, by using Presto ${ }^{\mathrm{TM}}$ Mini gDNA Bacteria Kit (Geneaid, USA). For this purpose, the MRSA strains were inoculated into $2.0 \mathrm{ml}$ of Tripticase Soy Broth (TSB) and incubated at $37^{\circ} \mathrm{C}$ for 20 hours. Procedure for the DNA extraction was performed according to the manufacturer guidelines. The integrity and concentration of the extracted DNA were checked by NanoDrop and gel electrophoresis.

Real-time PCR: For detection of the mecA and PVL genes all the isolates were analysed by CFX96 Realtime PCR detection system (Bio-Rad, USA) using specifically synthesized primers, shown in the table I. The final volume of $25 \mu \mathrm{l}$ of PCR reaction mixture contained $12.5 \mu \mathrm{l}$ of GoTaq ${ }^{\circledR}$, qPCR Mastermix (Promega, USA), $8.5 \mu \mathrm{l}$ nuclease free water (Promega, USA), $2 \mu$ l of the template DNA and $1 \mu \mathrm{l}$ of each specific primer pairs. To justify the best annealing temperature for the system and primers, and to check the specificity of the primers, first, the system was run for the gradient test, then the Real-time PCR was run for each gene separately, according to the GoTaq ${ }^{\circledR}$ qPCR mastermix manufacturer's guideline with reaction conditions as explained in table II.

The same procedure and system were used for the detection of the mecA and $P V L$ gene. The data was analysed by using Bio-Rad CFX Manager software (version 3.0) and melt curve. To confirm the results from real-time $P C R$ and to make sure that the amplified products were the target genes, the realtime PCR products were resolved by $1.5 \%$ agarose gel electrophoresis with100 bp DNA ladder .

Table I: Specific primers for the mecA and $P V L$ genes

\begin{tabular}{|c|c|c|c|}
\hline $\begin{array}{l}\text { Target } \\
\text { gene }\end{array}$ & Sequence & $\begin{array}{l}\text { Product } \\
\text { size }\end{array}$ & Reference \\
\hline mecA & $\begin{array}{l}\text { F- } \\
\text { TCCAGAT- } \\
\text { TACAACTTCACCAGG } \\
\text { R- } \\
\text { CCACTTCATATCTT- } \\
\text { GTAACG } \\
\text { (Bioneer, Korea) }\end{array}$ & $162 \mathrm{bp}$ & 15 \\
\hline$P V L$ & $\begin{array}{l}\text { F- } \\
\text { TTCACTATTT- } \\
\text { GTAAAAGTGTCAGACCC } \\
\text { ACT } \\
\text { R- TACT- } \\
\text { AATGAATTTTTTTATCGT } \\
\text { AAGCCCTT } \\
\text { (Bioneer, Korea) }\end{array}$ & $180 \mathrm{bp}$ & 16 \\
\hline
\end{tabular}

Table II: Real time PCR reaction conditions

\begin{tabular}{llll}
\hline Process & Cycles & Temperatures & Time \\
\hline $\begin{array}{l}\text { Hot-Start } \\
\text { Activation }\end{array}$ & 1 & $95 \mathrm{C}$ & 2 minutes \\
$\begin{array}{l}\text { Denaturation } \\
\begin{array}{l}\text { Annealing/ } \\
\text { Extension }\end{array}\end{array}$ & 40 & $95 \mathrm{C}$ & 15 seconds \\
Dissociation & 1 & $60 \mathrm{C}$ & 60 seconds \\
\hline
\end{tabular}

\section{RESULTS}

In this study 36 MRSA isolates from patients of both genders and of different age groups were procured. The patients were admitted to different wards, including: surgical (6 patients), orthopaedic (5 patients), obstetrics and gynaecology (2 patients), paediatrics ( 2 patients), internal medicine ward ( 9 patients), outpatients department (3 patients), intensive care unit ( 3 patients), cardiology (5 patients) and skin ward (1 patient). The origins of the samples were blood (17 samples), sputum (2 samples), swabs (8 samples), pus (1 sample), soft tissue ( 3 samples), tracheal aspirate (4 samples) and bronchial lavage (1 sample). Based on the abovementioned criteria in this study 16 out of $36(44.4 \%)$ isolates were CA-MRSA strains and 20 out of 36 (55.6\%) isolates were HA-MRSA strains. The results of the antibiotic susceptibility test by the disc-diffusion method and E-test (only for oxacillin and 
vancomycin) are shown in table III. The antibacterial drug susceptibility test results in the table are categorized as resistant, susceptible and intermediate according to the CLSI guideline on the interpretation of inhibition zone diameters as stated in a study. ${ }^{14}$

In the E-test all the tested isolates were considered as oxacillin resistant, as their MIC was $>4.0 \mu \mathrm{g} / \mathrm{ml}$. Conversely, all the tested isolates were considered as susceptible to vancomycin as their MIC was $<2$ $\mu \mathrm{g} / \mathrm{ml}$. Multi-drug resistant groups of isolates are illustrated in figure $\mathrm{I}$.

All 36 MRSA isolates were found to harbor the mecA gene as revealed by the real-time PCR. The presence of the mecA gene was confirmed by the melt curve analysis revealing a single peak and agarose gel electrophoresis showing the expected 162 bp amplicon band. Similar confirmation was done for the PVL gene resolving the $180 \mathrm{bp}$ amplicon. All the PCR tests were done in triplicate. The PVL gene was detected in only 4 out of 36 isolates $(14.4 \%$ of all tested isolates). The $P V L$ gene positive strains were obtained from patients with localized soft tissue infections and sepsis, related to the CA-MRSA. There was no $P V L$ positive strain in the HA-MRSA strains in this study.

\section{DISCUSSION}

$S$ aureus is the most common isolated pathogen from the clinical specimens. Resistance to the available beta-lactam antibiotics has increased the clinical importance of this strain. ${ }^{17}$ Furthermore, the plethora of reports on multiple-drug resistant MRSA has escalated the alarm about MRSA infections. The emergence of CA-MRSA strains in a hospital setting had made it difficult to distinguish CA-MRSA from the HA-MRSA strains. ${ }^{12}$ Moreover, the presence of the $P V L$ gene in MRSA has added on concerns about this pathogen. ${ }^{18}$ Detection of $P V L$ positive HA-MRSA has raised the concerns about the spread of higher virulence multi-drug-resistant strains of MRSA in hospitals. ${ }^{10}$ Published reports show the higher prevalence of $P V L$ positive MRSA strains in the Asian countries. ${ }^{19}$ Looking at these findings this study addressed the antibiotic susceptibility pattern and genetic characterization of MRSA isolates in the study area. The majority of the MRSA isolates in this study were from patients in internal medicine wards. A similar finding was reported by Ghanznavi in a study conducted in Kuala Lumpur Hospital, Kuala Lumpur, Malaysia. ${ }^{20}$ Based on the criteria pointed by Chen, ${ }^{12}$ in this study, 16 out of 36 isolates were CAMRSA $(44.4 \%)$ while the rest $(55.6 \%)$ were HA-MRSA. However, the rate of CA-MRSA and HA-MRSA is different from area to area, ${ }^{12}$ in a study the rate of HA-MRSA has been reported $59 \%$ from a tertiary teaching hospital in Malaysia. ${ }^{21}$ Previous studies have shown that the usual HA-MRSA strains had been spreading to the community while the common CAMRSA strains had been spreading to the hospitals. ${ }^{22}$ Therefore, it might be difficult to consider a MRSA strain as a CA-MRSA or HA-MRSA based on the data collected from patients. In this study, most of the CA-MRSA strains were related to the skin and soft tissue infections. However, there are reports on vancomycin-resistant and intermediately resistant (VISA and heterogeneous VISA) strains of MRSA in Malaysia and elsewhere in the world. ${ }^{23}$ In this study, vancomycin was found as the only antibiotic with no resistant strain to it, probably due to the strict control of its use in Malaysia.

As the disc diffusion method can only provide limited qualitative information on the susceptibility pattern to vancomycin, in this study, we opted for the quantitative E-test but did not go further than that for detection of VISA and hetero VISA. In this regard, this study finding was concordant with that of the study conducted in a tertiary teaching hospital in Malaysia. ${ }^{21}$ This study shows that vancomycin is still the anti-staphylococcal drug option with the highest efficacy. This study found clindamycin as the second most effective antistaphylococcal antibiotic among the tested antibiotics as $83.33 \%$ of isolates were susceptible to it. Others have also reported high rates of the susceptibility of MRSA to clindamycin. ${ }^{24}$ This study found that all the $P V L$ positive MRSA were susceptible to clindamycin. Resistance to chloramphenicol was also low (11.11\%) but higher than to clindamycin. This study found that only a few of the tested strains were sensitive and intermediately sensitive to erythromycin $(8.33 \%$ and $8.33 \%$ respectively). However, a study has reported full resistance to erythromycin in a tertiary hospital in Malaysia. ${ }^{5}$ Overall, the study findings show that most of the tested MRSA were resistant to multiple classes of antibiotics. In this study, we labeled the isolates which were resistant to three or more classes of antibiotics as multidrug-resistant, according to the study published by Saidi. ${ }^{13}$ 
Table III: The results of the antibiotic susceptibility test

\begin{tabular}{|c|c|c|c|c|c|c|}
\hline \multirow[t]{2}{*}{ Antibacterial drugs } & \multicolumn{2}{|c|}{ Sensitive } & \multicolumn{2}{|c|}{ Tntermediate } & \multicolumn{2}{|c|}{ Resistant } \\
\hline & $\mathrm{N}^{*}$ & $\%$ & $\mathrm{~N}$ & $\%$ & $\mathrm{~N}$ & $\%$ \\
\hline Oxaciltin (OX) & $0 / 36$ & $0 \%$ & $0 / 36$ & $0 \%$ & $36 / 36$ & $100 \%$ \\
\hline Gentamicin (CN) & $2 / 36$ & $5.55 \%$ & $2 / 36$ & $5.55 \%$ & $32 / 36$ & $88.88 \%$ \\
\hline Erythromycin (E) & $3 / 36$ & $8.33 \%$ & $3 / 36$ & $8.33 \%$ & $30 / 36$ & $83.33 \%$ \\
\hline $\begin{array}{l}\text { Trimethoprim- } \\
\text { sulfamethoxazole (SXT) }\end{array}$ & $12 / 36$ & $33.33 \%$ & $0 / 36$ & $0 \%$ & $22 / 36$ & $61.11 \%$ \\
\hline Chloramphenicol (C) & $28 / 36$ & $77.77 \%$ & $4 / 36$ & $11.11 \%$ & $4 / 36$ & $11.11 \%$ \\
\hline Tetracycline (TE) & $6 / 36$ & $16.66 \%$ & $2 / 36$ & $5.55 \%$ & $28 / 36$ & $77.77 \%$ \\
\hline Vancomycin (V) & $36 / 36$ & $100 \%$ & $0 / 36$ & $0 \%$ & $0 / 36$ & $0 \%$ \\
\hline Cefoxitin (FOX) & $0 / 36$ & $0 \%$ & $0 / 36$ & $0 \%$ & $36 / 36$ & $100 \%$ \\
\hline Clindamycin (DA) & $30 / 36$ & $83.33 \%$ & $1 / 36$ & $2.77 \%$ & $5 / 36$ & $13.88 \%$ \\
\hline Penicillin (P) & $0 / 36$ & $0 \%$ & $0 / 36$ & $0 \%$ & $36 / 36$ & $100 \%$ \\
\hline
\end{tabular}

This study illustrates that the resistance pattern of MRSA strains varies so much among isolates from different patients so that prescription of antibiotic to MRSA infections based on the general background information cannot be the most effective approach. In this study, all MRSA isolates were characterized by real-time PCR. As dyes like SYBR@ Green I may bind to unspecific amplified dsDNA ${ }^{25}$, therefore, for higher confidentiality about the specific amplification, in addition to the analysis of the real-time PCR products by Bio-Rad CFX Manager software (version 3.0) and melt curve, the identity of the products were confirmed by gel-electrophoresis using a 100bp DNA ladder, as recommended by Broeders. ${ }^{26}$

Figure I: Multidrug-resistant isolates grouped according to the number of different antibiotics they resist

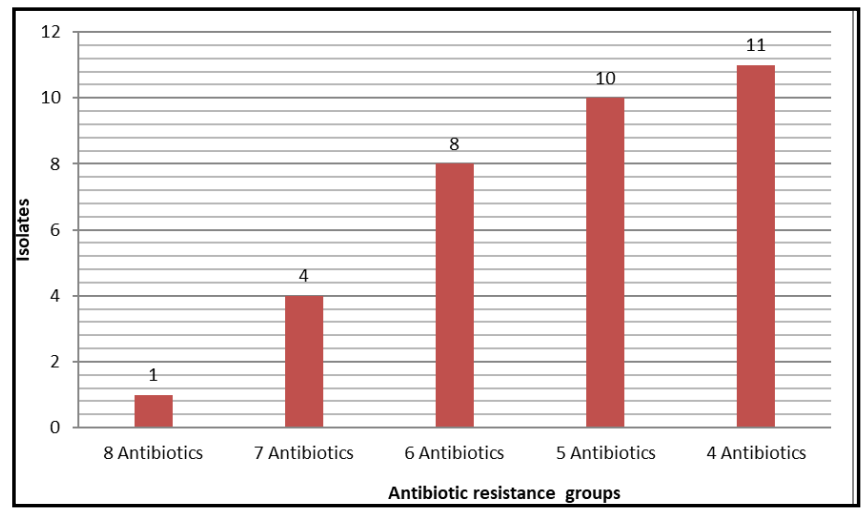

All those strains which were detected as MRSA by the phenotypic tests were detected as mecA positive. Similar findings have been reported from other Asian countries. ${ }^{3}$ Similarly, a study conducted by Nezhad in Iran, has reported that all the isolates of MRSA, which had been confirmed as resistant to oxacillin on phenotypic base, harbored the mecA gene detectable by PCR. ${ }^{16}$ However, the prevalence of $P V L$ positive MRSA differs geographically, overall, the Asian countries are reported to have a higher prevalence of $P V L$ positive MRSA. ${ }^{10}$ In a European multicenter study, inter-country variation in $P V L$ rates among MRSA strains has been reported to vary from $0 \%$ to $29 \% .{ }^{27}$ In our study $3 \mathrm{PVL}$ positive strains were isolated from the patients with skin and soft tissue infections and one from a patient with sepsis.

All PVL positive strains were from CA-MRSA strains. This study shows a much lower percentage of $P V L$ positive MRSA than the study finding in Nepal $(56.8 \%){ }^{28}$ The study in Nepal reported that $89.9 \%$ of the PVL positive strains were susceptible to clindamycin. The prevalence they have reported is much higher than the prevalence in this study, probably due to geographical variation. The PVL positive strains among MRSA isolates have been reported at a rate of $10.5 \%$ from a hospital in Turkey. ${ }^{29}$ In Malaysia, the study published by San Sit reported $5.3 \%$ of $P V L$ positive MRSA strains from a tertiary hospital. ${ }^{21}$ Another study from Malaysia reported $5.5 \% \quad P V L$ positive MRSA strains. ${ }^{30}$ Geographical and sample type and size differences might be the factors that explain the discrepancies in $P V L$ rates. 
This study explains the antibiotic susceptibility profile of MRSA strains to the commonly used antistaphylococcal antibiotics in the study area. The study also illustrates that the resistance to methicillin is mecA mediated, and there are PVL positive strains of MRSA in the study area.

\section{RECOMMENDATIONS}

Prescription of antibiotics in MRSA infections should be based on proper antibiotic susceptibility test results. Regular studies on the genetic characterization of MRSA strains are needed in the study area to add knowledge about the epidemicity of MRSA strains and to detect the emergence of new strains with modified mecA gene in the study area. Furthermore, a study of the PVL gene in MSSA strains is also recommended in the same study area.

\section{ETHICAL CONSIDERATION}

Before carrying this study, all required approvals were achieved from the relevant committees and authorities as follows:

KRC : Kulliyyah of Medicine Research Committee IREC : IIUM Research Ethics Committee NMRR : National Medical Research Register MREC : Medical Research \& Ethics Committee CRC: Clinical Research Committee

\section{ACKNOWLEDGEMENT}

The authors would like to thank the Research Management Centre at IIUM, Kuantan for the financial support under (RIGS 16-298-0462), the Kulliyyah of Medicine at International Islamic University Malaysia, and Pathology Department in HTAA for their technical support.

\section{REFERENCES}

1. Konaté K, Mavoungou JF, Lepengué AN, et al. Antibacterial activity against $B$-lactamase producing Methicillin and Ampicillin-resistants Staphylococcus aureus: fractional Inhibitory Concentration Index ( $\mathrm{FICl}$ ) determination. Annals of clinical microbiology and antimicrobials 2012;11:18.

2. Al-Zoubi MS, Al-Tayyar IA, Hussein E, Al Jabali A, Khudairat S. Antimicrobial susceptibility pattern of Staphylococcus aureus isolated from clinical specimens in Northern area of Jordan. Iranian journal of microbiology 2015;7:265.

3. Karmakar A, Dua P, Ghosh C. Biochemical and Molecular Analysis of Staphylococcus aureus Clinical Isolates from Hospitalized Patients. Canadian Journal of Infectious Diseases and Medical Microbiology 2016;2016.

4. Ike B, Ugwu MC, Ikegbunam $M N$, et al. Prevalence, Antibiogram and Molecular Characterization of Comunity-Acquired Methicillin-Resistant Staphylococcus Aureus in AWKA, Anambra Nigeria. The open microbiology journal 2016;10:211.

5. Al-Talib H, Al-Khateeb A, Hassan $\mathrm{H}$. Antimicrobial resistance of Staphylococcus aureus isolates in Malaysian Tertiary Hospital. International Medical Journal 2015;22:1-3.

6. Gardete S, Tomasz A. Mechanisms of vancomycin resistance in Staphylococcus aureus. The Journal of clinical investigation 2014;124:2836-40.

7. Liu Y, Zhang J, Ji Y. Suppl-1, M2: PCR-based Approaches for the Detection of Clinical Methicillin-resistant Staphylococcus aureus. The open microbiology journal 2016;10:45.

8. Monecke S, Gavier-Widen D, Mattsson R, et al. Detection of mecC-Positive Staphylococcus aureus (CC130-MRSA-XI) in Diseased European Hedgehogs (Erinaceus europaeus) in Sweden. PLOS ONE 2013;8:e66166.

9. Kerschner $\mathrm{H}$, Harrison EM, Hartl R, Holmes MA, Apfalter P. First report of mecC MRSA in human samples from Austria: molecular characteristics and clinical data. New microbes and new infections 2015;3:4-9.

10. Hu Q, Cheng H, Yuan W, et al. PantonValentine leukocidin (PVL)-positive health careassociated methicillin-resistant Staphylococcus aureus isolates are associated with skin and soft tissue infections and colonized mainly by infective PVL-encoding bacteriophages. Journal of clinical microbiology 2015;53:67-72.

11. Abimanyu N, Krishnan A, Murugesan S. Use of triplex PCR for rapid detection of PVL and differentiation of MRSA from methicillin resistant coagulase negative staphylococci. Journal of clinical and diagnostic research: JCDR 2013;7:215.

12. Chen CJ, Huang YC. New epidemiology of Staphylococcus aureus infection in Asia. Clinical Microbiology and Infection 2014;20:605-23. 
13. Saidi R, Cantekin Z, Khelef D, Ergün $Y$, Solmaz $\mathrm{H}$, Kaidi R. Antibiotic susceptibility and molecular identification of antibiotic resistance genes of staphylococci isolated from bovine mastitis in Algeria. Kafkas Üniversitesi Veteriner Fakültesi Dergisi 2015;21:513-20.

14. STAMDARDS A. Performance standards for antimicrobial susceptibility testing. Approved Standards CLSI 2010:M100-S20.

15. Stegger á, Andersen P, Kearns A, et al. Rapid detection, differentiation and typing of methicillin-resistant Staphylococcus aureus harbouring either mecA or the new mecA homologue mecALGA251. Clinical Microbiology and Infection 2012;18:395-400.

16. Nezhad RR, Meybodi SM, Rezaee R, Goudarzi M, Fazeli M. Molecular characterization and resistance profile of methicillin resistant Staphylococcus aureus strains isolated from hospitalized patients in intensive care unit, Tehran-Iran. Jundishapur Journal of Microbiology 2017;10.

17. Ramazanzadeh R, Salimizand H, Shahbazi B, Narenji H. Prevalence of mecA Gene of Methicillin Resistant Staphylococcus spp. Isolated from Nosocomial Infections and Environmental Specimens in Sanandaj Hospitals, Kurdistan, Iran. Research in Molecular Medicine 2015;3:38-42.

18. Millar EV, Rice GK, Elassal EM, et al. Genomic Characterization of USA300 MethicillinResistant Staphylococcus aureus (MRSA) to Evaluate Intraclass Transmission and Recurrence of Skin and Soft Tissue Infection (SSTI) Among High-Risk Military Trainees. Clinical Infectious Diseases 2017:cix327.

19. Lari AR, Pourmand MR, Ohadian Moghadam S, Abdossamadi Z, Namvar AE, Asghari B. Prevalence of PVL-containing MRSA isolates among hospital staff nasal carriers. Laboratory Medicine 2015;42:283-6.

20. Ghaznavi-Rad E, Shamsudin MN, Sekawi Z, et al. Predominance and emergence of clones of hospital-acquired methicillin-resistant Staphylococcus aureus in Malaysia. Journal of clinical microbiology 2010;48:867-72.

21. San Sit P, Teh CSJ, Idris N, et al. Prevalence of methicillin-resistant Staphylococcus aureus (MRSA) infection and the molecular characteristics of MRSA bacteraemia over a two -year period in a tertiary teaching hospital in Malaysia. BMC infectious diseases 2017;17:274.
22. Molton JS, Tambyah PA, Ang BS, Ling ML, Fisher DA. The global spread of healthcare-associated multidrug-resistant bacteria: a perspective from Asia. Clinical infectious diseases 2013;56:1310-8.

23. Brooks G, Carroll KC, Butel J, Morse S. Jawetz Melnick\&Adelbergs Medical Microbiology 26/E: McGraw Hill Professional; 2012.

24. Kaur N, Prasad R, Varma A. Prevalence and Antibiotic Susceptibility Pattern of Methicillin Resistant Staphylococcus aureus in Tertiary Care Hospitals. 2014.

25. Vandesompele J. qPCR guide. Eurogentec EUA 2008.

26. Broeders S, Huber I, Grohmann L, et al. Guidelines for validation of qualitative realtime PCR methods. Trends in Food Science \& Technology 2014;37:115-26.

27. Bouchiat C, Curtis S, Spiliopoulou I, et al. MRSA infections among patients in the emergency department: A European multicentre study. Journal of Antimicrobial Chemotherapy 2016:dkw431.

28. Bhatta DR, Cavaco LM, Nath G, et al. Association of Panton Valentine Leukocidin (PVL) genes with methicillin resistant Staphylococcus aureus (MRSA) in Western Nepal: a matter of concern for community infections (a hospital based prospective study). BMC infectious diseases 2016;16:199.

29. Ozekinci T, Dal T, Yanik K, et al. PantonValentine leukocidin in community and hospitalacquired Staphylococcus aureus strains. BIOTECHNOLOGY \& BIOTECHNOLOGICAL EQUIPMENT 2014;28:1089-94.

30. Neela V, Moghaddam HG, van Belkum A, HorstKreft D, Mariana NS, Rad EG. First report on methicillin-resistant Staphylococcus aureus of Spa type T037, Sequence Type 239, SCCmec type III/IIIA in Malaysia. European journal of clinical microbiology \& infectious diseases 2010;29:115. 
